\title{
OS BENEFICIÁRIOS DA AÇÃO AFIRMATIVA ${ }^{1}$
}

\author{
OCKERT DUPPER ${ }^{2}$
}

\begin{abstract}
RESUMO: Na África do Sul pós-apartheid a Ação Afirmativa destaca-se como um tema bastante controverso e de amplos contornos. No presente artigo, limitado ao contexto trabalhista, pretende-se salientar questões críticas a respeito da forma que a ação afirmativa é atualmente implementada, bem como indicar quem são e quem deveriam ser os beneficiários desta política. Por certo, a indicação dos beneficiários da ação afirmativa somente será possível se consideradas as contínuas mudanças nas relações sociais e econômicas da sociedade. PALAVRAS-CHAVE: Ação Afirmativa; Beneficiários.
\end{abstract}

ABSTRACT: In South Africa post-apartheid, the Affirmative Action stands out as a very controversial issue and the broad outlines. In this article, limited to the labor context, it is intended to highlight critical issues about the way that affirmative action is actually implemented, and indicate who they are and who should be beneficiaries of the policy. Of course, details of beneficiaries of affirmative action will only be possible when considering the ongoing changes in social and economic relations of society.

KEYWORDS: Affirmative Action; Beneficiaries.

SUMÁRIO: Introdução; 1 A Questão "quem"; 2 Alguns Comentários Conclusivos - E Alguns Indicadores para o Futuro; Referências.

SUMMARY: Introduction; 1 The "who" Question; 2 Some Concluding Remarks And Some Pointers for the Future; References.

\section{INTRODUÇÃo}

Não seria um exagero dizer que a ação afirmativa apareceu como uma das questões mais controversas na África do Sul pós-apartheid. Este capítulo origina-se no fato de que a reparação ou ação afirmativa são necessárias e

Artigo recebido em 19.05.2012. Artigo aceito para publicação em 17.06.2012 mediante convite. 1 Publicado originalmente por DUPPER, Ockert. The Beneficiaries of Affirmative Action. In: DUPPER, Ockert; GARBERS, Cristoph. Equality in the Workplace: reflections from South Africa and beyond. Cidade do Cabo: Juta \& Co. Ltd, 2009. Traduzido por Maria Carolina Rosa de Souza. Mestranda pela Pontifícia Universidade Católica do Rio Grande do Sul - PUCRS. Especialista em Direito Processual Civil pelo Instituto Meridional - IMED, 2010. Graduada em Ciências Jurídicas e Sociais pela Universidade de Passo Fundo - UPF, 2007. Advogada integrante da banca Carles de Souza Advogados Associados. mariacarolsouza@yahoo.com.br ${ }^{2}$ Mestre e Doutor em Direito pela Harvard Law School. Professor de Direito do Trabalho e da Seguridade Social na Universidade de Stellenbosch. Diretor do Centro de Direito Internacional e Comparado do Trabalho e da Seguridade Social na mesma universidade. 
justas como medida corretiva para o legado do colonialismo e apartheid. Entretanto, precisamos apresentar questões críticas a respeito da atual maneira em que a ação afirmativa é implementada, se devemos evitar uma situação na qual a ação afirmativa se torne uma política que somente gere ressentimento e reforce, ao invés de enfraquecer, as divisões sociais existentes.

Assinala-se que o significado das medidas de ação restitucionárias ou afirmativas e suas áreas de aplicação no contexto sul-africano são amplas. Este capítulo, entretanto, focará na implementação da política no contexto trabalhista e em uma questão em particular: nos beneficiários da ação afirmativa. O capítulo conterá componente descritivo, crítico e normativo. Detalhará quem são os atuais beneficiários da ação afirmativa na África do Sul, criticará a insuficiência do foco atual e fará sugestões experimentais a respeito de quem deveriam ser os beneficiários da ação afirmativa.

\section{A QUESTÃO "QUEM"}

A Constituição deixa a identidade dos potenciais beneficiários da ação afirmativa deliberadamente vaga e em aberto, referindo-se a "pessoas ou categorias de pessoas em desvantagem pela discriminação injusta"3. A Lei 55 da Igualdade no Trabalho de 1998 (EEA), entretanto, é menos cautelosa em sua abordagem, e identifica três categorias muito distintas de desvantagem que garantem a reforma - raça, gênero, deficiência. ${ }^{4} \mathrm{O}$ ato, portanto, reconhece pessoas negras, mulheres de todas as raças e pessoas com deficiências como os potenciais beneficiários da ação afirmativa no local de trabalho. Na categoria "negra" pretende-se incluir todos aqueles previamente classificados como "africanos", "de cor" e "indígenas", significando que ela reproduz quais são, de fato, as mesmas categorias e divisões raciais que apoiaram o apartheid ${ }^{5}$. Além disso, em um julgamento recente, a Suprema Corte North Gauteng declarou que os sul-africanos de origem chinesa também entram na definição de pessoas "negras", em razão da Lei da Igualdade no Trabalho e do Ato para o Empoderamento Econômico dos Negros de $2003 .{ }^{6}$

Evidências sugerem que a implementação vigente favorece "raça" sobre "gênero" e "deficiência", e "africano" sobre "de cor" e "indígena"”. Isto não

\footnotetext{
${ }^{3}$ Seção 9(2).

${ }^{4}$ Seção 1.

${ }^{5}$ Ver o Ato 30 do Registro da População de 1950, seção 1 (iii), (x) e (xv). Ver, também, Posel "What"s in a Name? Racial Categorizations under Apartheid and their Afterlife" (2001) 47. Transformation 50-56.

${ }^{6}$ Associação Chinesa da África do Sul X Ministério do Trabalho, caso 59251/2007 (TPD); [2208] ZAGPHC 174. Antes de 1994, os chineses eram privados da cidadania oficialmente classificados como "de cor". Embora eles fossem isentos de certas restrições provenientes de sua classificação racial, sua "identidade intersticial" (preto para alguns propósitos e branco para outros), aumentou sua invisibilidade e resultou na indignidade de estar à mercê da misericórdia do Estado oficial e das comunidades brancas na sua negociação do sistema de permissão e isenções não oficiais.

${ }^{7}$ Ver Bentley \& Habib, "Racial Redress, National Identify \& Citizenship in Post-Apartheid South Africa" em Bentley \& Habib (eds) Racial Redress and Citizenship in South Africa (HSRC 2008) 12. Ver também MacDonald Why Race Matters in South Africa (Universidade de Harvard, em 2006) 174.
} 
deveria ser uma surpresa porque, recentemente, em 2005, o Congresso Nacional Africano reconfirmou que a questão nacional na África do Sul é sobre a liberação da maioria africana ${ }^{8}$. Além disso, a decisão do Congresso Nacional Africano no final da década de 1970 para endossar o uso do termo "negro" para se referir a africanos, de cor, e indígenas pelo movimento da consciência negra foi contestado e permanece assim até hoje. Muitos acreditam que isso generalizou a experiência política dos três grupos, minimizando suas locações variantes na estrutura hierárquica da opressão racial do apartheid ${ }^{9}$. Também implica em uma reivindicação igual à reforma pós-apartheid, sem levar em consideração a severidade da opressão racial dos africanos e as vantagens desfrutadas pelos de cor e indígenas ${ }^{10}$. Essa tensão está atualmente também refletida na discussão sobre os chamados "graus de desvantagem", que perdeu a eficácia nos tribunais e fóruns de arbitragem, onde os planos da ação afirmativa que priorizam africanos sobre os outros grupos designados foram justificados na base da desvantagem relativa de africanos frente aos de cor e indígenas ${ }^{11}$.

Implícito na previsão constitucional está o reconhecimento de que a desvantagem e a desigualdade assumem formas particularmente complexas na África do Sul, e que as medidas de ação afirmativa podem ser moldadas para uma variedade de grupos, contanto é claro que eles tenham sido prejudicados por uma "discriminação injusta". Em Van Heerden, o Tribunal Constitucional endossou a exclusão da seção 9(2) afirmando que seu propósito é reformar as desvantagens baseando-se não somente na raça, mas também no gênero, na classe e em outros níveis e formas de diferenciação social e o desprivilegio sistêmico que ainda persiste. ${ }^{12} \mathrm{Em}$ outras palavras, há um reconhecimento de que a desvantagem não somente segue a questão da raça, mas que as divisões raciais estão entrelaçadas com os divisores rural-urbano, gênero, classe, regional e cultural, os quais complicam a natureza da desvantagem e a discriminação ${ }^{13}$.

A ênfase exclusiva na ação afirmativa baseada na raça nega esta complexidade e potencialmente exclui alguns dos beneficiários que mais

\footnotetext{
${ }^{8}$ Ver Bentley \& Habib (nota 6 acima) 2.

${ }^{9}$ Ndletyana "Affirmative Action in the Public Service: Unresolved Tension between Nativity and Non-racialism within African Nationalism" em Bentley \& Habib (eds) Racial Redress and Citizenship in South Africa 55.

${ }^{10}$ Idem.

${ }^{11}$ Ver, por exemplo, Motala and Another X University of Natal 1995 (3) BCLR 374 (D); Mclnnes X Technikon Natal (2000) 21 ILJ 1138 (LC); Fourie X Provincial Commissioner of the SA Police Service (North West Province) and Another (2004) 25 ILJ 1716 (LC); Public Service Association - Gerhard Koorts X Free State Provincial Administration CCMA FS3915, 21 de maio de 1998; Solidarity on behalf od Christiaans and Eskom Holdings Ltd (2006) 27 ILJ 1291 (ARB).

${ }_{12}$ Minister of Finance and Another X Van Heerden 2004 (6) SA 121 (CC) para 27 (per Moseneke J). ${ }^{13}$ Ver Report of the Presidential Commission to Investigate Labour Market Policy (junho de 1996). Para uma discussão da complexa natureza das inequidades na África do Sul, ver Liebenberg \& Goldblatt "The Interrelationship Between Equality and Socio-Economic Rights under South Africa"s Transformative Constitution" (2007) 23 SAJHR 335, 335-336.
} 
merecem as medidas da reforma. O foco atual na raça como o ponto de reforma está baseado na suposição de que o estado do apartheid foi em primeira instância racialmente exclusiva, negando direitos econômicos e políticos iguais a uma população negra, e somente em segundo lugar economicamente exploradora ${ }^{14}$. Se isto for correto, a política de reforma pareceria muito mais com a política atual, isto é, que tenha como objetivo fazer os locais de trabalho refletirem a demografia racializada da sociedade sul-africana. Entretanto, esta interpretação da natureza do apartheid é divergente. Muitos discutem que ela relacione-se, também, com a exploração de classe, separação espacial, dominação de gênero e articulação complexa destes e outros elementos ${ }^{15}$. Esta interpretação favoreceria uma abordagem mais matizada para a ação afirmativa - envolvendo a necessidade de estudar cada domínio no qual a ação afirmativa deve ser desenvolvida em detalhe, a fim de identificar as reais fontes de desvantagem sofrida pelos indivíduos e grupos relevantes ${ }^{16}$.

O significado de repetir a rede racial do apartheid em busca da reforma pode também ter implicações importantes na busca do não racismo, o qual é a principal meta de uma estratégia baseada na raça ${ }^{17}$. Esta abordagem instrumental de usar a raça para superar os efeitos da discriminação racial pode ser melhor exemplificada pela declaração de Justice Blackmun da Suprema Corte dos Estados Unidos, que "a fim de ir além do racismo, devemos levar a raça em consideração" ${ }^{18}$. Em Van Heerden, o Tribunal Constitucional endossou esta abordagem instrumental, com relação à reforma baseada na raça como o meio para alcançar o fim não racial ${ }^{19}$. Sendo instrumental, esta abordagem requer que avaliemos se os programas de ação afirmativa baseados na raça têm o potencial de trazer à tona o ideal não racial. Se acontecer, por exemplo, de eles exacerbarem o preconceito e a hostilidade racial, tornando mais difícil a existência de uma sociedade verdadeiramente não racial, é uma razão que vai contra o desejo instrumental

\footnotetext{
${ }^{14}$ Maré "The State of the State: Contestation and Race Re-assertion in a Neoliberal Terrain" em Daniel e outros (eds) State of the Nation: South Africa 2003-2004 (HSRC) 25-33.

${ }^{15}$ Maré "Race Counts inContemporary South Africa" (2001) 47 Transformation 75-90.

${ }^{16}$ Ver Alexander "Affirmative Action and the Perpetuation of Racial Identities in Post-Apartheid South Africa, palestra apresentada no East London Campus of the University of Fort Hare, 25 de março de 2006, 11.

${ }^{17}$ Ver Van Heerden (acima) parag. 44 (per Moseneke J). Defensores da ação afirmativa nos Estados Unidos argumentam no mesmo sentido de Dworkin: "programas de ações afirmativas utilizam critério explicito de raça porque seu objetivo imediato é aumentar o número de membros de certas raças na profissões. Mas seu objetivo de longo prazo é reduzir o grau pelo qual a sociedade americana é no geral uma sociedade racialmente consciente". Ver Dworkin "Bakke"s Case: Are Quotas Unfair?" em Cahn (eds) The Affirmative Action Debate (Routledge 2002) 111.

${ }^{18}$ Ver Regents of the University of Califórnia X Bakke 438 US 265, 407 (1978) (Blackmun J, plurality opinion).

${ }_{19}$ Por exemplo, em Van Heerden (acima), a Corte se referiu a uma sociedade não racial como "o objetivo condicional de longo prazo", que deve ser levado em conta no julgamento de se uma medida reparatória, no longo prazo, promoverá a equidade. Ver para 44 (per Moseneke J).
} 
dos programas baseados na raça ${ }^{20}$. Isto não resolveria a questão, é claro, pois pode haver também considerações nas quais os programas baseados na raça antecipariam a vinda de uma sociedade não racial, por exemplo, redistribuindo posições de poder e autoridade aos negros, criando previamente modelos não disponíveis e mudando vastamente atitudes preconceituosas vastamente tomadas ${ }^{21}$.

Enquanto a maioria das pessoas hoje proclama o comprometimento com uma sociedade não racial, o significado do termo permanece alusivo e é raramente questionado. Isto é muito curioso, porque a Constituição identifica "não racismo" como um "valor de base"22. Está claro que, para o termo "não racismo" ter algum significado, deve significar mais do que "não racismo" porque, do contrário, como MacDonald destaca "não xenófobos poderiam se chamar não racistas e acabar com a questão"23. A nova ordem constitucional declara-se anti-racista e não racial, confirmando que os dois termos não se referem a fenômenos idênticos ${ }^{24}$. O "não racismo" é, portanto, um ideal que tem dois objetivos em seu âmago, a saber, superar o racismo e erradicar o racismo oficial. Entretanto, qualquer que seja o significado técnico, o termo "não racismo" é entendido por muitos na África do Sul como pessoas que são afastadas da preocupação com a raça. Especialmente para as minorias deste país, "o não racismo" significa o que parece significar: "a negação, ou o esforço para negar, o significado social de raça" ${ }^{25}$.

${ }^{20}$ Ver Wasserstrom "Racism, Sexism, and Preferential Treatment: An Approach to the Topics" 24 UCLA Law Reports (1976-1977) 581, 616.

${ }^{21}$ Ver Dupper "Remedying the Pasto $r$ Reshaping the Future? Justifying Race based Affirmative Action in South African ant the United States" (2005) 21 The International Journal of Comparative Labour and Industrial Relations 89-130. Ver também as contribuições de Sandra Fredman para a elaboração de dos benefícios adicionais da ação afirmativa.

${ }_{22}$ Seção 1(b) da Constituição de 1996 afirma que a África do Sul é um Estado Democrático soberano, fundado num número de valores que incluem o "não racismo e não sexismo". Nota-se que isso é uma situação rara "porque devem haver poucas, se alguma, sociedades que declararam o não racismo como uma política prioritária". Ver Taylor \& Foster "Advancing Non-racialism in Post-apartheid South Africa" em Palmberg (ed) National Identity and Democracy in South Africa (HSRC 1999) 328-329.

${ }^{23}$ Ver Mac Donald Why Race Matters in South Africa 93. Por um período, os líderes da ANC ficaram confinados a esse significado restrito. Em uma conferência de imprensa em Lusaka, em 1985, Oliver Tambo, então presidente da ANC respondeu como segue a uma questão que para explicar as diferenças entre não racialismo e multiracionalismo: "deve haver uma diferença. Que é porque nós dizemos não racialismo e não multiracialismo... Nós queremos dizer racial do que multiracial. Nós dizemos não racial - não há racismo. Multiracial não responde a questão de racismo. Não racial sim. Não haverá racismo de nenhum tipo e além disso nenhuma discriminação que proceda do fato das pessoas serem membros de raças diferentes. Isso é o que nós entendemos por não racial". Ver Press conference, Lusaka, 25 de junho, 1985 http://www.anc.org.za/ancdocs/history/or/or85-7.html (own emphasis added).

${ }^{24}$ Seção 1 da Constituição refere-se aos valores de "não racialismo" e "não sexismo"; não "racismo e não sexismo". Porém é interessante notar que em Van Heerden (acima), Justice Sachs em um lugar parece utilizar os dois termos alternadamente, se referindo ao "objetivo condicional de atingir uma sociedade igualitária baseada no não racismo e não sexismo" (para 136) e no próximo parágrafo ao termo "não racialismo" (para 137).

${ }^{25}$ Mac Donald. Op. cit. 174. 
Até que ponto, então, a ação afirmativa baseada na raça contribui com este ideal? Ao responder esta pergunta, torna-se aparente que enquanto houver um compromisso retórico com a meta de uma sociedade não racial, um debate aberto sobre as implicações da ação afirmativa baseada na raça para esta meta é tão raro que "pode muito bem não acontecer" 26 . Frequentemente a ligação entre os dois é vista como auto-evidente. Uma escrutinização mais detalhada, entretanto, revela que essa ligação é complexa, baseada em um entendimento particular de "não racismo". Enquanto o "não racismo" pode seguir como uma "linha indestrutível" através da história do Congresso Nacional Africano ${ }^{27}$, seu significado nunca permaneceu estável. Foi continuamente modificado e reapresentado por uma variedade de razões, sendo não menos importante que a experiência prática da luta contra o apartheid. O conceito de não racismo que se desenvolve no curso da luta anti-apartheid durante os anos 80 pode ser descrito como transformador. $\mathrm{O}$ não racismo como um ideal de transformação da sociedade se refere a um processo no qual um compromisso com a erradicação das duas práticas de apartheid e o sistema de ideias no que se refere à "raça" nos quais estas práticas foram construídas, é complementado por um programa combinado para fornecer uma ampla reforma para as desvantagens que a maioria dos sul-africanos sofreram no passado ${ }^{28}$. Por este olhar, longe de evitar a adoção de políticas racistas, o princípio do não racismo diferentemente torna-o um elemento essencial. Simplificando, a discussão sobre o não racismo é absurda no contexto de uma sociedade caracterizada por profundas desigualdades socioeconômicas arraigadas que são amplamente baseadas na raça. A menos que estas desigualdades baseadas na raça sejam reformadas por meio de medidas baseadas na raça, como um comentarista notou, "os brancos permanecerão os sujeitos e os negros os objetos, como era antes" ${ }^{\prime 29}$. Isto significa que reivindicações pela exclusividade racial inerentes na reforma baseada na raça podem funcionar, paradoxalmente, como um meio através do qual os prejudicados pressionam por uma desracialização adequada da sociedade.

Entretanto, há certamente custos significativos envolvidos na repercussão das categorias raciais do apartheid. Uma das consequências de tornar estas categorias salientes é que isso dá a elas, tomando emprestada a frase

\footnotetext{
${ }^{26}$ Maré. Op. cit. 89.

27 Essa é a reivindicação que Julie Frederikse faz em seu livro, The Unbreakable Thread: Non-racialism in South Africa (Indiana University, 1990). É uma reivindicação disputada. Se tal característica duradoura da ANC, alguns comentaristas questionam por que a ANC esperou até 1969 para adotar uma política destituída de filiação com relação aos brancos e outros membros racialmente designados? Ver Bernstein "The Breakable Thread" (março, abril 1991). The Southern African Review of Books. 3, 20-21 (citado em Ndebele "The African National Congress and the Policy of Non-racialism: a Study of the Membership Issue" (2002) 29 (2) Politikon, 133, 134).

${ }^{28}$ Ver Sharp "Non-racialism and its Discontentes: a Post-apartheid Paradox" (1998) 50 (156) International Social Science Journal 243.

${ }^{29}$ MacDonald. Op. cit. 176.
} 
de Melissa Noble, uma "ilusão da mediocridade" ${ }^{30}$, o qual previne uma consideração crítica e reflexiva da existência significativamente social das raças. Raça - especialmente a idéia que a sociedade sul-africana é composta de quatro raças distintas - é simplesmente um fato na maneira na qual pensamos em sociedade. Torna-se um hábito de pensamento e experiência, uma faceta do "senso comum" diário, uma explicação de eventos, comportamentos, o passado, o presente e o futuro que é considerado adequado e óbvio, não exigindo nenhuma elaboração ${ }^{31}$. Além disso, dá legitimidade às categorizações de raça bioculturais completamente desacreditadas, o que pode ser uma das ironias mais perturbadoras da reforma pós-apartheid ${ }^{32}$. Não há necessidade de questionar as atribuições de raça do apartheid, como o presente nos fornece uma continuidade consistente, aceitando a validade e a habilidade de reconhecer as raças que são tão necessárias para as políticas baseadas nesta construção ${ }^{33}$. Estudos também indicam que as pessoas ainda reivindicam exageradamente uma identidade racializada como seu meio de auto-descrição ${ }^{34}$. Isto não deveria ser uma surpresa porque "a banalidade diária da classificação da raça" ${ }^{, 35}$ permeia a África do Sul regularmente: desde satisfazer as exigências do EEA, até a aceitação ou recusa da admissão em universidades, registros de nascimentos, responder a pesquisas de censo todas exigem a especificação de "raça" ou "grupo populacional" ou "grupo étnico" (onde todos estes tem o mesmo significado) ${ }^{36}$.

Certamente uma reforma baseada na raça pode ter contribuído para um ideal de não racismo de outras maneiras. O valor de tornar o local de trabalho e instituições educacionais mais racialmente representativas pode dificilmente ser subestimado. Fornece uma oportunidade para uma interação individualizante entre os membros de diferentes grupos e para a criação de fontes conectadas de identidade social, o qual, enquanto não há garantia de

\footnotetext{
${ }^{30}$ Nobles Shades of citizenship: Race and Census in modern Politics (Stanford University, 2000) 180, como citado em Maré. Op. cit. 82.

${ }^{31}$ Ver Maré. Op. cit. 89-90; Posel. Op. cit. 51.

${ }^{32}$ Posel. Op. cit. 71.

${ }^{33}$ Maré. Op. cit. 89. Como Posel aponta, esse implora a uma questão muito importante (mas ignorada ou escondida), denominada como, numa era pós apartheid, nós determinamos quem é "africano", "de cor", "branco" e "índio"? Ao contrario da época sob apartheid, não é tão fácil alocar as pessoas em caixas raciais porque o registro populacional do ato 30 de 1950 , que aloca as pessoas em diferentes grupos não existe mais. Ver Posel. Op. cit. 68. Além disso, como bem indica, "se o projeto pos apartheid é bem sucedido e a segregação entre as raças diminui (ou até desaparece totalmente), se tornara impossível o cumprimento de políticas e leis que dizem respeito a classificação racial, porque a segregação dura e rápida que o apartheid impôs está suposta a desaparecer. Ver Bentley "Rethinking the ultimate Goal of Affirmative Action: Who and What is it for", paper preparado para $61^{\text {st }}$ Harold Wolpe Memorial Trust Open Dialogue, 19 de julho de 2002, p. 2.

${ }^{34}$ Ver Zegeye, Liebenberg \& Houston "Resisting Ethnicities fro Above: Social identities and democracy in South Africa" in Muthien e outros. Democracy and Governance Review: Mandela's Legacy. 1994-1999 (HSRC 2000) 164.

${ }^{35}$ Maré. Op. cit. 82.

${ }^{36}$ Idem.
} 
eliminar o preconceito intergrupo, são inquestionavelmente necessários para este fim $^{37}$. A teoria da identidade social sugere que a classificação de membros de diferentes categorias sociais em situações envolvendo interdependência cooperativa e interações sociais individualizantes também parecem reduzir a resposta categórica ${ }^{38}$.

Pode muito bem ser que no caso particular da África do Sul, os custos associados com a abordagem baseada na raça teriam que ser significativos a fim de superar os benefícios. Após décadas de classificações raciais formais, em consonância com alguns dos bens sociais mais fundamentais da África do Sul, tais como emprego, terra, moradia e educação foram distribuídos, somente espera-se que estas categorias raciais preservarão proeminência na sociedade sul-africana num futuro próximo. Estes "grupos raciais" eram, na realidade, criados pela prática injusta de discriminação racial original e negar o fato (perseguindo uma política de "daltonismo" ou negando a existência de raças) seria a negação de uma realidade social uma realidade que não pode ser moralmente ignorada enquanto os erros que as criaram não tenham sido retificados ${ }^{39}$. Mesmo assim, ainda que esta visão seja aceita, ela não nos alivia do peso de assegurar que nas palavras de Justice Sachs, "a criança do não racismo não seja descartada com a água da ação paliativa" ${ }^{40}$. Pode aparecer um ponto onde os benefícios da reforma baseada na raça não mais supere o dano do sentimento da perpetuação da raça. A este respeito, o Estado Democrático tem uma responsabilidade particular - uma vem do poder político numérico - de remodelar a maneira pela qual nós nos identificamos. Se for acordado que as identidades não são dadas, mas construídas, o Estado tem o papel vital de criar sul-africanos não raciais através da completa cidadania no estado universal ${ }^{41}$. Se, entretanto, acontecer de o não racismo do estado ser meramente formal, segue, como MacDonald destaca, "que as pessoas não raciais permanecerão meramente formais também" ${ }^{\prime 2}$.

${ }^{37}$ Ver Hamilton Krieger "Civil Rights Perestroika: Intergroup Relations After Affirmative Action" (1998) 86 California Law Reports 1251, 1276.

${ }^{38}$ Hamilton Kroeger. Op. cit. 1251,1276.

39 Ver Dupper "In Defence of Affirmative Action in South Africa" (2004) 121 SALJ 187, 213. Isso, é claro, não significa deduzir que categorias raciais têm referentes científicos fixos, além da presença de genes para meras características morfológicas com a cor da pele ou as características faciais. Isso é meramente apontar o vago e incontificável conjunto de características que a sociedade sul africana associa com varias identidades raciais, tem tido, e continua a ter, um impacto dramático na vida das pessoas. Nesse respeito, concorda-se com a reivindicação de Christopher Ford, no sentido de que raça é real enquanto, ao mesmo tempo, completamente ilusória. Ver Ford "Challenges and Dilemmas of Racial and Ethnic Identity in American and Post-Apartheid South African Affirmative Action" (1996) 43 UCLA Law Report 1953, 2000. Para a discussão da contingência de identificação racial, ver Gutman "Responding to Racial Injustice", e Appiah "Race, Culture, Identity: Misunderstood Connections"em Appiah \& Gutman. Color Conscious (Sage 1996) 30-105.

${ }^{40}$ Van Heerden, acima, 137.

${ }^{41}$ Ver Alexander. Op. cit. 11.

${ }^{42}$ Mac Donald. Op. cit. 174. 


\section{ALGUNS COMENTÁRIOS CONCLUSIVOS - E ALGUNS INDICADORES PARA O FUTURO}

Finalmente, retornando à tese apresentada anteriormente, de que a desigualdade e a desvantagem têm causas complexas. Se formos sérios na abordagem da desvantagem em toda a sua complexidade, então a reforma baseada na raça parece um instrumento verdadeiramente ineficaz. Isto se torna ainda mais aparente à medida que o projeto de transformação atual começa a mudar as relações sociais e econômicas da nossa sociedade. Economistas como Sampie Terreblanche e Nicoli Nattrass destacaram que enquanto a lacuna entre os negros e brancos diminuiu em anos recentes (embora ainda permaneça uma questão preocupante) houve um aumento significativo nos níveis de desigualdade dentro dos grupos raciais, especialmente entre os africanos ${ }^{43}$. Assim, enquanto a desigualdade interracial declinou, a desigualdade intra-racial aumentou. Enquanto essa desigualdade intra-racial tem suas origens nas mudanças políticas e econômicas que ocorreram durante os últimos vinte anos de apartheid, aumentou significativamente durante os últimos quinze anos à medida que o projeto de reforma baseado na raça começa a surtir efeito ${ }^{44}$. A ação afirmativa foi notavelmente bem sucedida na desracialização do cume da estrutura da classe, mas deixou os níveis mais baixos amplamente intocados ${ }^{45}$. Enquanto a criação de uma elite negra pode ser um imperativo moral e estratégico importante na África do Sul $^{46}$, o processo de criação desta elite destacou as limitações de uma estratégia exclusivamente baseada na raça ${ }^{47}$. Ele criou um pequeno grupo de "informantes" cada vez mais multi-raciais que participam e se beneficiam da prosperidade na

${ }^{43}$ Ver Terreblanche. The History of Inequality in South Africa: 1652-2002 (University of Natal 2002) 447-448; Alexander. Op. cit. 400; Seekings \& Nattrass Class, Race and Inequality in South Africa (Yale University, 2005) 307-308.

${ }^{44}$ Terreblanche (nota 42, acima) 133. Mais amplamente, a medida utilizada do grau inequidade de distribuição de renda é o coeficiente Gini. Quanto menor o valor coeficiente Gini, mais proporcional é a distribuição de renda. Um Gini de zero denota uma perfeita equidade (todos os indivíduos na população receberam mesma renda). Enquanto um Gini de 1 denota uma perfeita inequidade (um individuo na população recebe tudo). O coeficiente Gini mais recente figura como segue: Africanos 0.63; De Cor 0.59; Índio 0.57; Branco 0.56. Ver Statistics South Africa Income and Expenditure of Households 2005/2006: Analysis of Results (2008) 35.

${ }^{45}$ Bentley \& Habib (nota 6, acima) 12.

${ }^{46}$ Ver Terrablanche (nota 42, acima) 133, Bentley \& Habib "Na Alternative Framework for Redress and citizenship', em bentley \& habib (eds) Racial Redress and citizenship in South Africa (HSRC 2008) 232; MacDonald (nota 6, acima) 150, 154-158.

${ }^{47}$ Como Benatar afirma, "[Aqueles que são mais sem vantagem por injustiça são tão sem vantagens que não podem sequer começar a competir por posições que beneficiários da ação afirmativa racial obtém. Benetar. Affirmative Action Not the Way to trckle Injustice. Palestra inaugural na University of Cape Town, 11 de abril de 2007. Esse argumento também tem ecos no debate dos Estados Unidos. Ver, por exemplo, Fullilove X Klutznick 448 US 448, 538 (1980) (Stewart, J) (Aqueles que são os mais sem vantagem.....são os menos prováveis receptores de qualquer beneficio do privilégio especial) e a discussão em kennedy "Persuasion and Distrust: A Comment on the Affirmative Action Debate"(1986) 99 Harward Law Review 1327, 1333-1334. 
África do Sul, enquanto que o grupo maior de "forasteiros" que são pobres, desempregados, e desproporcionalmente rurais e jovens, permanece quase que exclusivamente negro ${ }^{48}$. As mudanças contínuas nas relações sociais e econômicas da África do Sul como uma consequência das estratégias atuais de reforma baseadas na raça exigem uma reavaliação das próprias estratégias.

Esta reavaliação deveria reviver a classe como uma ferramenta de análise na África do Sul - algo que, desde 1994, foi amplamente relegado ao passado, onde ocupava um papel central na análise do apartheid e na construção de visões para o futuro ${ }^{49}$. Com exceção dos Estados Unidos, onde a ação afirmativa baseada na classe ou no status socioeconômico beneficiará desproporcionalmente os brancos que, por simples força numérica, ainda são a maioria dos pobres naquele país ${ }^{50}$, o apartheid e a segregação legaram à África do Sul uma estrutura de classe que é ampla, embora de maneira alguma exclusiva, racialmente definida. Como Adam Habib destaca, esta ampla sobreposição entre raça e categorias de classe "permite uma situação onde uma estratégia de reforma com objetivos de classe em seu âmago teria em substância o efeito de mediar as disparidades raciais históricas...sem reforçar as identidades raciais e agravar o racismo" ${ }^{\prime 51}$. Também deve haver uma vantagem estratégica para a utilização das considerações socioeconômicas ao invés da raça como a base de uma estratégia de reforma. Em uma análise recente de uma variedade de pesquisas, Steven Friedman e Zimitri Erasmus concluem que enquanto há um grau de abertura para a reforma por parte dos sul-africanos brancos, esboçando exclusivamente em termos raciais não é a maneira mais efetiva de assegurar sua condescendência. Então, quando possível, eles discutem, "a reforma tem pelo menos uma probabilidade de enfrentar resistência onde as medidas que serviriam para reformar as desigualdades raciais podem ser

\footnotetext{
${ }^{48}$ MacDonald (nota 6, acima) 158, Ver Seekings \& Nattrass (nota 42, acima) 343.

${ }^{49}$ Maré aponta que a escrita anti apartheid, até a transição de 1994, foi preenchida com amplo e intenso debate na essencialidade da natureza de classe exploradora da África do Sul capitalista. Ver Maré (nota 47, acima) 87.

${ }^{50}$ Porém, também deve ser apontado que embora haja mais brancos pobres do que pobres latinos ou negros, as taxas de pobreza branca são menores do que aquela dos dois últimos grupos. Ver Malamud "Assessing Class-Based Affirmative Action"(1997) 47 Journal of Legal Education 452-465.

${ }^{51}$ Habib "Conversations with a Nation: Race and Redress in South Africa", em Pieterse \& Meintjies (eds) Voices of the Transition: The Politics, Poetics and Practies of Social Change in South Africa (Heinemann 2004) 247. Neville Alexander argui que no contexto da África do Sul por causa do fato demográfico da maioria negra nesse estágio de evolução da consciência cultural populacional, a estratégia seria igualmente efetiva e mais pecisamente focada no nível dos beneficiários individuais se grupos de classe ou renda fossem utilizados como a principal meta do programa. A grande área de sobreposição entre raça e classe na África do Sul faz esta possível abordagem. Além disso, isso seria possível para todos os indivíduos economicamente sem vantagem, independente de cor, de se beneficiarem dos programas que derivam dessa estratégia. Alexander. Implications of Brown v Board of Education: A Post-Apartheid South Africa Perspective. PRAESA Occasional Papers, $\mathrm{n}^{\circ}$ 20, 2004. 16.
} 
redigidas como medidas anti-pobreza ao invés de medidas de reversão do poder e privilégio racial, mesmo se isto for fundamentalmente a meta" ${ }^{\prime \prime 2}$.

O que a análise evidencia é a necessidade de uma abordagem mais matizada da ação afirmativa - uma que considere a complexidade da desvantagem e das mudanças contínuas acontecendo em nossas relações sociais e econômicas ${ }^{53}$. A este respeito, muito pode ser aprendido do exemplo indiano. A Índia enfrentou, com alguma sofisticação, a questão se grupos diferentes/particulares têm diferentes necessidades pela ação afirmativa. A Índia mantém uma lista extensiva de grupos menos favorecidos e usa fatores empíricos, incluindo discriminação social, a privação educacional e o status econômico, para determinar o status do grupo. Alguns grupos os mais prejudicados - têm suas próprias quotas independentes, geralmente proporcionais à população. Outros grupos também receberam uma taxa, porém menor do que a quota de sua população. Direitos individuais podem depender se os indivíduos relevantes foram criados em circunstâncias privilegiadas. Assim, há um método cuidadoso, elaborado e bastante refinado de determinar como a ação afirmativa neutralizará ou até mesmo acabará com a desvantagem ${ }^{54}$.

Isto requer a pergunta: quão receptivo é o governo a uma abordagem alternativa e mais matizada na ação afirmativa? Muitas pessoas destacaram que as complexas razões políticas e econômicas limitam severamente a habilidade do governo de manobrar, e pode levar a um entrincheiramento das atuais políticas baseadas na raça ${ }^{5}$. Muito foi escrito a respeito da economia imensamente desigual herdada pelo Congresso Nacional Africano em 1994, e a respeito da natureza do compromisso que foi alcançado com capital e o estado do apartheid. Ao concordar em respeitar o "mercado" e implementar políticas neo-liberais paralelas à oferta em troca do consentimento de estado e capital para a democracia, o Congresso Nacional Africano severamente limitou sua habilidade de restringir as desigualdades econômicas e erradicar a pobreza ${ }^{56}$. Isto torna ainda mais importante as

\footnotetext{
52 Friedman \& Erasmus "Couting on "Race": What the Surveys Say (and Do Not Say) about "Race" and "Redress"', in Bentley \& Habib (eds). Racial Redress and Citizenship in South Africa (HSRC 2008) 41.

${ }^{53}$ Embora as vias alternativas específicas pra usar a raça como meio primário de reparação, não são diretamente o interesse aqui, vale a pena apontar que elas envolvem não apenas uma abordagem baseada na classe discutida acima, mas também uma agenda de reparação baseada na classe suplementada por mais iniciativas específicas baseadas na raça (Bentley \& Habib (nota 51, acima) 232); uma baseada na divisão urbano-rural (Maré (nota 14, acima) 90); uma baseada na língua (Alexander (nota 15, acima) 11), etc. Essas abordagens dividem a mesma premissa denominando que as causas profundas de inequidade são complexas e consequentemente requerem soluções inovadoras e matizadas e em contextos específicos.

${ }^{54}$ Ver Cunningham \& Madhava Menon. "Race, Class, Caste...? Rethinking Affirmative Action" (1999) 97 Michigan Law Report 1296; Sustein "Affirmative Action, Caste, and Cultural Comparisons" (1999) 97 Michigan Law Report 1311-1316.

${ }^{55}$ Ver Dupper (nota 38, acima) 214.

${ }^{56}$ Ver, MacDonald (nota 6, acima) 172-174; Terreblanche (nota 42, acima) 439.
} 
melhorias que aconteceram, a saber, a ampliação da composição racial da elite. Sob estas circunstâncias de opções limitadas, a estratégia de abranger a política de identidade como uma alternativa para uma ampla redistribuição econômica serve bem ao governo. Como MacDonald nota, o racismo opera em uma lógica tentadora, porque "defende que ajudar alguns membros de um grupo, ajuda o grupo; e ajudar o grupo, ajuda todos os seus membros"57. Em outras palavras, a suposição é que todas as pessoas negras se beneficiam quando algumas delas se juntam à elite capitalista. Esta suposição de uma identidade compartilhada de interesse de todos os negros serve para legitimar a exclusão da maioria dos negros de dividir os benefícios de redistribuição ${ }^{58}$.

O Ministro do Trabalho recentemente anunciou que a ação afirmativa nunca seria revogada ${ }^{59}$. Há duas maneiras de interpretar esse comentário. Dada as realidades política e econômica recém descritas, pode ser visto como um aval da continuidade das estratégias atuais baseadas na raça. Entretanto, uma interpretação alternativa, talvez menos plausível do que a primeira, porém mais discutida neste capítulo é visualizá-la como um reconhecimento de que as mudanças nas relações sociais e econômicas resultantes das estratégias de reforma baseadas na raça podem necessitar de uma reflexão das próprias estratégias ${ }^{60}$. Isto implicaria de o Ministro poder estar correto: enquanto o fim da ação afirmativa como a conhecemos pode estar próximo, medidas de reforma que respondam de uma maneira focada e refinada às formas de mudança complexas e contínuas de desigualdade na África do Sul podem muito bem estar aqui para ficar.

\section{REFERÊNCIAS}

ALEXANDER. SEEKINGS \& NATTRASS. In: Class, Race and Inequality in South Africa. Yale University, 2005.

ALEXANDER. Implications of Brown v Board of Education: A Post-Apartheid South Africa Perspective. PRAESA, 2004.

BENTLEY \& HABIB. Racial Redress, National Identify \& Citizenship. In PostApartheid South Africa, 2006.

BENTLEY \& HABIB. Racial Redress and Citizenship in South Africa, 2008.

CUNNINGHAM \& MADHAVA MENON. Race, Class, Caste...? Rethinking Affirmative Action, In: Michigan Law Report, 1999.

DUPPER, Ockert. Defence of Affirmative Action in South Africa, 2004.

\footnotetext{
${ }^{57}$ MacDonald (nota 6, acima) 175.

${ }^{58}$ Como Walter Benn Michaels aponta no contexto americano: "Raça..... tem sido uma... tecnologia bem sucedida de mistificação....um dos grandes usos do racismo era [e é] induzir pessoas brancas pobres para sentir um crucial e inteiramente um companheirismo razoável com pessoa brancas ricas; uma das grandes utilizações do anti-racismo é fazer pessoas pobres pretas se sentirem com igual companheirismo razoável com pessoa ricas pretas. Ver Michaels "What Matters" London Review of Books, 27 de agosto de 2009.

${ }^{59}$ Ver "No Stopping Affirmative Action yet" Pretoria News (7 de março de 2007).

${ }^{60}$ Ver a contribuição de Sandra Fredman para este volume, no qual aponta que uma separação entre status e desvantagem deve ter lugar como resultado de políticas de ações afirmativas.
} 
DUPPER, Ockert. Remedying the Pastor Reshaping the Future? Justifying Race based Affirmative Action in South African ant the United States. In: The International Journal of Comparative Labour and Industrial Relations, 2005.

DWORKIN, Ronald. Bakke's Case: Are Quotas Unfair?. In: Cahn. The Affirmative Action Debate, 2002.

FRIEDMAN \& ERASMUS. Couting on "Race": What the Surveys Say (and Do Not Say) about "Race" and "Redress". In: Bentley \& Habib. Racial Redress and Citizenship in South Africa, 2008.

FORD. Challenges and Dilemmas of Racial and Ethnic Identity in American and PostApartheid South African Affirmative Action. Law Report, 1996.

GUTMAN. Responding to Racial Injustice., e Appiah. Race, Culture, Identity: Misunderstood Connections. In: Appiah \& Gutman. Color Conscious, 1996.

HABIB. Conversations with a Nation: Race and Redress in South Africa. In: PIETERSE \& MEINTJIES. Voices of the Transition: The Politics, Poetics and Practies of Social Change in South Africa, 2004.

KRIEGER, Hamilton. Civil Rights Perestroika: Intergroup Relations After Affirmative Action. California Law Reports ,1998.

MACDONALD. Why Race Matters in South Africa. Harvard University, 2006.

MALAMUD. Assessing Class-Based Affirmative Action. In: Journal of Legal Education, 1997.

MARÉ. The State of the State: Contestation and Race Re-assertion in a Neoliberal Terrain. In: Daniel et. al. State of the Nation: South Africa, 2003-2004.

MARÉ. Race Counts in Contemporary South Africa. In: Transformation, 2001.

MICHAELS. What Matters. In: London Review of Books, 2009.

NDLETYANA. Affirmative Action in the Public Service: Unresolved Tension between Nativity and Non-racialism within African Nationalism. In: Bentley \& Habib. Racial Redress and Citizenship in South Africa, 2008.

NOBLES. Shades of Citizenship: Race and Census in modern Politics. Stanford University, 2000.

POSEL. What"s in a Name? Racial Categorizations under Apartheid and their Afterlife. In: Transformation, 2001.

SHARP. Non-racialism and its Discontentes: a Post-apartheid Paradox. In: International Social Science Journal, 1998.

SUSTEIN. Affirmative Action, Caste, and Cultural Comparisons. In: Michigan Law Report, 1999.

TAYLOR \& Foster. Advancing Non-racialism in Post-apartheid South Africa". In: Palmberg. National Identity and Democracy in South Africa, 1999.

TERREBLANCHE. The History of Inequality in South Africa: 1652-2002. University of Natal, 2002.

WASSERSTROM. Racism, Sexism, and Preferential Treatment: An Approach to the Topics. In: Law Reports, 1976-1977.

ZEGEYE, LIEBENBERG \& HOUSTON. Resisting Ethnicities fro Above: Social identities and democracy in South Africa. In: Muthien et.al. Democracy and Governance Review: Mandela's Legacy, 2000. 